\title{
Developing a language support model for mainstream primary school teachers
}

Child Language Teaching and Therapy $x *(x)_{2} 1-16$

(C) The Author(s) 2010 Reprints and permission: sagepub. co.uk/journalsPermissions.nav DOI: 10.1 I 77/0265659010369306 http://clt.sagepub.com

@SAGE

\author{
Elspeth McCartney, Sue Ellis, James Boyle, \\ Mary Turnbull and Jane Kerr \\ University of Strathclyde
}

\begin{abstract}
In the UK, speech and language therapists (SLTs) work with teachers to support children with language impairment (LI) in mainstream schools. Consultancy approaches are often used, where SLTs advise educational staff who then deliver language-learning activities. However, some research suggests that schools may not always sustain activities as planned. There is a need to consider teachers' views on implementing consultancy approaches, and use these to develop practical means to set-up, monitor and evaluate classroom-based language-learning activities, developing a 'language support model' useful to teachers. The small-scale study described aimed to investigate and analyse teachers' and SLTs' views, and to use these to develop a language support model suited to the ecology of the primary classroom. A small-scale participatory evaluation study is reported. Participants were three community SLTs, and mainstream primary teachers experienced with children with LI: four teachers from one authority who had been involved in a previous language-learning trial, and I5 teachers from three other authorities. Methods were short questionnaire, group interview and iterative document revision. On the basis of participants' views, a flexible language support model was developed. This model outlines school and SLT actions needed to implement and monitor language activities and to check progress, with related materials for teachers. The language support model reflected participants' views of the realities of classroom work, and the materials were judged useful to teachers. They have been edited and published for general use.
\end{abstract}

\section{Keywords}

intervention efficacy, specific language impairment, speech and language therapy

\section{Background}

In the UK, most children of primary school age with severe and persistent language impairment are educated in their local mainstream school, in line with policies of social inclusion. Mainstream

\section{Corresponding author:}

Elspeth McCartney, Speech and Language Therapy Division, Educational and Professional Studies Department, University of Strathclyde, 76 Southbrae Drive, Glasgow, GI 3 IPP, UK

Email: e.mccartney@strath.ac.uk 
schooling provides social and educational benefits, and legal responsibility for meeting any child's educational needs resides with their school (DfES, 2001; Scottish Executive, 2002). The listening and speaking curriculum is designed to develop children's language skills (LTS, 2008; QCA, 2008). There is also advice for teachers on how to include and support children with difficulties (QCA, 1999; LTS, 2000). For children with additional support needs, co-professional working is also expected (DfES, 2004; Scottish Executive, 2004).

Responsibility for fostering language and communication development for children with persisting difficulties is shared amongst education staff and speech and language therapists (SLTs), and with families. The SLT professional body, the Royal College of Speech and Language Therapists (RCSLT), suggests that over time many children will follow a trajectory from SLT-led to school-led provision (Gascoigne, 2006: 12).

Where school and SLT staff are involved in delivering language-learning activities, the most common UK approaches are 'consultancy' models. These can take many forms, but in principal SLTs give advice and guidance to classroom staff, who carry out relevant language-learning activities (Law et al., 2002). However, despite relevant policies, curriculum guidance and established co-professional practices, the Bercow review of services for children and young people with speech, language and communication needs in England found unacceptable variation and lack of equity in the provision offered to children (DCSF, 2008: 61). It also found examples of good practice.

Despite the importance of teachers in fostering language learning, there is very little research on their perspectives, or how they approach working with SLTs. This article reports on a small-scale research project that elicited the views of mainstream classroom teachers involved in co-working with SLTs. The research was carried out following two intervention trials undertaken by the authors for children with primary language impairment: an RCT and a cohort study, with measured differences in outcomes. These trials are fully described elsewhere, but are briefly summarized here to set the scene for the present study.

\section{Two previous intervention trials}

Child participants in two previous intervention trials were children with persistent expressive language impairment (E-LI) or receptive-expressive language impairment (RE-LI) that interfered with academic achievement and social communication, causing functional difficulties in school. Children in both studies were aged 6-11 years, attended their local mainstream primary school, and scored $<-1.25$ standard deviation (SD) on the receptive and/or expressive scales of the Clinical Evaluation of Language Fundamentals (CELF-3 UK; Semel et al., 2000, adjusted norms 2003), a standardized test of language understanding and use. They had documented normal hearing and no neurological impairment, pervasive developmental disorder, or severe learning difficulties as measured by non-verbal IQ scores $75 \leq$ on the WASI (Wechsler, 1999). They had no speech, fluency, swallowing or alternative/augmentative communication needs nor any other factors that would require the specific skills and knowledge of an SLT. They were therefore children whose language development needs could reasonably be accommodated in the primary classroom.

The first intervention study was a randomized controlled study (RCT) (Boyle et al., 2007; Boyle et at., 2008), which compared randomly allocated delivery of language-learning activities by an SLT with delivery by an SLT assistant (SLTA), and both modes were delivered to children individually or in small groups. The study was controlled by a fifth set of children randomly allocated to continue with their 'usual therapy'. Principal outcome measures were scores on the CELF-3 UK immediately after therapy, and at 12 months follow-up. Children carried out language activities from a specially written therapy manual covering comprehension monitoring and the development 
of vocabulary, grammar and narrative, with advice for teachers on how to create a 'communication friendly' classroom. This Language Therapy Manual is available at http://uk.sitestat.com/strathelyde/sth-

There were 124 children who completed research intervention. They were scheduled for three 30-40 minute sessions weekly over 15 weeks, i.e. a maximum of 45 sessions, and the mean obtained was 38 (range 13-45). They therefore received around 22 hours of intervention on average.

However, the 31 one RCT control children who continued their 'usual therapy' from their local SLT services mostly received consultancy approaches, with advice and guidance given to their school staff and families, and logged much less contact with an SLT than those receiving research intervention. An audit of contact with SLT services across a school year (around 40 weeks) obtained data for 28 control children and showed that half (14) had received no SLT or SLTA contact. The others averaged 16 contacts with an SLT or SLTA, equivalent to some six contacts over 15 weeks, a period during which research children had averaged 22 hours of contact.

Results immediately after intervention showed no difference in CELF-3 UK scores amongst children in the four research therapy modes, but benefits to expressive language compared to controls for the four research modes combined, after controlling for child language scores on entry (an effect size of +55 ). There was no significant benefit to receptive language for research intervention children compared to control children, and no significant receptive or expressive language gains for control children. Research intervention children's scores did not continue to accelerate during the 12-month follow-up period, although expressive language scores remained a little ahead of controls after 12 months, due to their higher starting point.

The RCT intervention therefore offered an efficacious therapy for children with E-LI, although not RE-LI, over the short term, but it had delivered a much larger amount of contact with SLT services than was received by 'usual therapy' control children.

This RCT used an 'extract' model of research intervention, rather than the more common consultancy approach. A second, cohort, study was therefore undertaken to investigate the outcomes of intervention based in the classroom, delivered by education staff (McCartney et al., 2009; press). Children from one Scottish authority who met the same language and other criteria as RCT children participated, with progress compared to the RCT control group. In addition, cohort study children were causing educational concern and were receiving school-based learning-support services to develop their literacy skills.

The cohort of children had language targets set by the research SLT in conjunction with their class teacher. Therapy intervention was in the same language areas; used language-learning activities from the same therapy manual as the RCT, with summary documents prepared as handouts for teachers; and materials from the therapy manual were provided by the research SLT for classroom use. The intention was to replicate RCT intervention procedures as far as possible, but with delivery by education staff. Activities were delivered by school staff, including learning-support teachers, class teachers and classroom assistants.

Thirty-eight children in 19 schools and 33 classes received intervention. There were no significant differences between cohort and RCT children in respect of gender, non-verbal IQ or expressive or receptive language scores on CELF-3 UK. Although within the same age range, cohort study children were some nine months older on average than RCT children. This was statistically significant, but chronological age had not affected response to intervention in the RCT (Boyle et al., 2007: 36). The children were therefore well matched at the start of the study.

However, the outcome of the cohort study differed from the RCT, in that following intervention there were no statistically significant changes in cohort study participants' scores on the CELF-3 UK, 
and no significant advantage for cohort participants relative to the RCT control group for either expressive or receptive language. Child progress in the classroom-based cohort study therefore was not particularly successful: although children fared as well as RCT control children receiving 'usual therapy', the significant gain in expressive language obtained in the RCT was not replicated.

\section{Differences in amount of targeted language-learning activity?}

One factor that might relate to this variation in outcomes was a difference in the amount of targeted language-learning activity documented. It was intended that children in the cohort study would undertake the same amount of activity on the same schedule as the RCT. Classroom staff were asked to log activities as they were carried out. Language activity logs (including one late response) were returned for 27 children (71\%) with comments included for 17 (45\%): remaining logs were not received or were incomplete. For completed logs the number of language-learning contacts recorded ranged from 8 to 70 , mean 26, over the four-month intervention period. The mean was therefore equivalent to one or two contacts per week, with the length of a language-learning session not usually noted.

These responses represent both a large difference compared to the RCT, and a large difference amongst cohort study children. Those getting most contacts recorded almost nine times as many as those who got least. School staff in the cohort study reported that activities had mostly been planned to take place two or three times a week, as recommended, but the available activity logs suggested this did not always happen. It is possible that more language work could have been carried out in class without being logged, and no data are available on how long children spent in total on language work. It is however unlikely that many children received the 22 hours of language-learning activity achieved in the RCT, and not all schools or classrooms had been able to act upon the advice given, despite planning to do so at the start of intervention. This may have been relevant to children's limited progress in expressive language. It appeared possible from the RCT to obtain shortterm gains in expressive language for children with persisting language impairment, but the results of the cohort study suggested that many schools had not found it easy to systematically deliver enough targeted language teaching. And both studies suggested that children whose language learning was not sustained, or was discontinued, failed to continue to progress.

Classroom teachers responded to questionnaires at the end of the cohort study, reporting on 24 children, 63\% of the total (McCartney et al., 2009: 84). Teachers of eight children mentioned time problems in carrying out the language work, and for 13 children teachers agreed or strongly agreed that 'this method of working expects too much of the teacher'. Views were therefore mixed, but some teachers at least had reservations about their ability to implement language work in the research study. Such teacher views will no doubt be important in sustaining consultancy approaches to language intervention. The views of community SLTs are also relevant.

A small-scale, evaluative study was therefore carried out to investigate and analyse teachers' and community SLTs' views concerning language intervention within consultancy models. A further aim was to use these perspectives to develop a model of classroom-based language support that could fit into to the ecology of the primary classroom.

\section{The evaluative study}

The evaluative study described here, entitled 'The development and validation of materials for use by classroom teachers working with children with primary language impairment', was carried out after the two studies described previously and in light of their findings. The aim of the evaluative study was to elicit SLTs' and classroom teachers' perspectives on delivering language-learning 
activities, and in particular their views on factors that would make undertaking language teaching easier for classroom staff. These views were used to construct, critique and evaluate a set of procedures that would enhance provision of language-learning activities in the classroom, and would give teachers information, materials and approaches that would lead to effective practice: i.e. to develop a validated language support model for teachers, based on the efficacious therapy procedures developed in the RCT outlined above.

\section{Methods}

\section{Study design}

The research design was participatory evaluation employing group interview. Teachers who had participated in the cohort study were first consulted, then teachers and community SLTs from authorities that had not been involved in the earlier research studies.

\section{Participants}

Two sets of mainstream primary school teachers participated. The first set self-selected from a list compiled by the cohort study research SLT of teachers who had actively engaged that study, and who were therefore experienced in organizing language-learning activities (experienced staff). A group of 6-8 teachers was sought in line with recommended numbers for group interview (Robson, 2002), and six were recruited. Four were able to attend all meetings. They were joined by the SLT who had acted as research SLT in the cohort study. These teachers may be assumed to represent those who had welcomed the language-teaching role and the contact with an SLT.

The second set of teachers came from three education authorities that had not taken part in the previous research studies (potential staff). They were self-selected volunteers, from schools listed by their cognate SLT service as having been involved at some time in consultancy approaches for children with language impairment. Around six teachers from each authority were sought and 15 were recruited, with one authority recruiting three. Some teachers had specific remits to educate children with additional support needs, or had additional management roles. Two community SLTs joined this set, which was at times divided into smaller groups for discussion. Potential staff had volunteered to participate, and so again will represent an interested and informed group.

\section{Ethical approval}

The study was given ethical approval by the Thames Valley Multi-Centre Research Ethics Committee (04/MRE12/55) following COREC procedures, and by University of Strathclyde departmental ethics procedures.

\section{Procedures}

Each set of participants met on three occasions, with experienced teacher meetings completed before potential teacher meetings began. This allowed an iterative process of discussion and document generation. Data was collected during meetings as field notes by two researchers. Short tasks and questionnaires were completed by participants before each meeting. Summaries of these and of meeting discussions were fed back to participants for member-checking of accuracy at subsequent meetings. The audit trail comprised participants' written responses to short tasks and 
questionnaires, researchers' notes and summaries of discussion and any participant amendments, and resulting revised documents.

\section{Aims and content of meetings}

The overall aim of the series of meetings was for participants to discuss the implementation of targeted language-learning activities in the mainstream primary school, based on the interventions and outcomes of the two studies summarized above. A further aim was to develop a set of improved procedures to encourage SLT and teacher co-working, and to help teachers implement language teaching in the school. The experienced teachers who had been involved in the cohort study provided a review and critique of the contact, co-working, monitoring and organizational procedures employed by that study, and of the documents provided for teachers, and of how activities from the therapy manual fitted into classroom work. They concentrated on suggesting improvements, reconfiguring procedures and re-drafting documents, or confirming the utility of existing practices.

Their revisions were then presented to the set of potential user teachers who considered how language support might fit into their broader range of classroom contexts, and further refined and developed practices and documents. Topics for each meeting and pre-meeting were selected to meet these aims: these appear in Table 1.

\section{Results}

\section{Experienced users' perspectives}

The ultimate outcome of this series of meetings is the language support model for teachers,avaitable from http://ww strath.ac.uk/eps/centresdivisions/stt/teachingresourees/lsm. This is the finat edited version resulting from the meetings outlined above. The final version contained a brief background introduction, and seven documents. The model gives information on how teacher and SLT partnerships can organize and monitor delivery of language-learning activities in mainstream schools, with outlines of teaching approaches and details of how the model was developed. The final list of documents appears in Table 2. Key points in the development of this model are outlined here, cross-referred to meeting discussions and the relevant documents in the model.

\section{Experienced users' contributions}

a Preliminary information needed: Participants who had been involved in the cohort study reflected upon their experiences, and outlined learning and personal changes that they had undergone. They were confident that teachers could organize relevant language-learning activity, and that they would welcome the opportunity to give practical help to a child. Their overall message was that many mainstream teachers would be unfamiliar with the language-learning activities used in the therapy manual, and new to working with SLTs. Such teachers would need clear explanations, tailored documents and detailed planning procedures in order to organize delivery of targeted language-learning activities, and to integrate language learning with classroom curricular activities. In the view of the experienced teachers, there had not been enough explanation for classroom teachers at the start of the cohort study about such issues. Experienced users felt that much more up-front information was needed for a teacher who was to undertake specific language work for children with LI, at least on first encounter.

These insights led to the development of the general introduction section of the model-(http:H

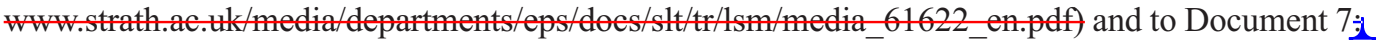


Table I. Meeting and pre-meeting topics

Pre-meeting topics

Experienced teachers:

Meeting I

Meeting 2

Meeting 3

Potential user teachers:

Meeting I

Meeting 2

Meeting 3

\author{
Written comment \\ on cohort study \\ documents for \\ teachers
}

Written comment on extracts from the Therapy Manual

Consider links with the school curriculum; Consider role of parent(s)/carer(s)
Written comments on the experiencedteachers' draft Language Support Model 3

Plan possible language activities for the 'pen portrait' child
Meeting discussion topics

- How to improve teacher documents

- Summary of cohort-study teachers' questionnaire responses

- Personal changes experienced by experienced-teacher participants during the cohort study

- Developing a language support model I

- Critique of therapy manual extracts

- Models of SLT/teacher collaboration

- Developing a language support model 2.

- Identifying links with the school curriculum

- Role of parent(s)/carer(s)

- Logging language-learning activities

- Reviewing selected published language materials.

- Developing a language support model 3

- Outline of the research projects and child examples

- Draft language support model 3

- How to manage/timetable language teaching in each participant's school

- Poster of main personal learning points

- Summation of posters and timetables from Meeting I

- Oral comments on the experiencedteachers' draft language support model 3

- Anonymized pen portrait of a child in the participant's class

- Introduction to the therapy manual extracts

- Obtaining published materials

- Critique of therapy manual extracts

- Discuss possible language activities for the 'pen portrait' child

- Summation of comments on the experienced teachers' draft language support model 3

- Design a 'dream service'

- Written 'last messages' 
Table 2: The language support model for teachers: Documents

\begin{tabular}{ll}
\hline Document & Topic \\
\hline Introduction & Start here \\
Document I & Introduction to the language support model \\
Document 2 & Creating a communication friendly classroom \\
Document 3 & Monitoring comprehension \\
Document 4 & Principles of vocabulary development \\
Document 5 & Principles of grammar development \\
Document 6 & Principles of oral narrative development \\
Document 7 & Development of the language support model \\
\hline
\end{tabular}

Bevelopment of the language suppert model (http://ww.strath.ac.uk/media/departments/epst does/stt/tr/1sm/media_61629_en.pdf). These would provide background written information for teachers new to the process.

b A series of planned SLT and school meetings: Experienced participants also considered that detailed consideration would have to be given to timetabling and staff availability to deliver language-leaning activities, and that these had to be agreed with the head-teacher as well as by the SLT and class teacher. They discussed monitoring implementation, to ensure that the planned programme of language activities was sustained, and ways in which teachers could seek rapid help and support from the SLT if the programme was not working as planned. They considered the setting of language targets, to take place as in the cohort study as a co-operative venture between the class teacher and SLT to ensure functional language learning, and how targets would be updated and changed. They therefore outlined a programme to manage language support for an individual child that detailed the meetings and discussions that should take place between a child's school staff and SLT to facilitate implementation of language teaching in the classroom, the documents that should be in place at each discussion, how parent(s) or carer(s) would be informed, the decisions that would be taken at each meeting, and how delivery would be monitored.

This programme was developed mainly from a class teacher's perspective. It was recognized that in consultancy approaches to language support children are identified as in need of language support at unpredictable and varied times in the school year, and that decisions about in-class language work are often made by those other than teachers (although best practice would suggest otherwise). For example, teachers may become involved only:

- after the parent(s) or carer(s) have given consent for a child's language abilities to be assessed;

- after an SLT has decided that SLT-specific skills are not required but in-class language support is recommended; and

- after a head-teacher has agreed it is feasible to deliver language work within the child's classroom.

This means that classroom teachers are frequently asked to organize the delivery of language activities at short notice, at a time when their detailed classroom plans and timetables have been completed and when learning-support and classroom-assistant time has already been allocated. Language activities for an individual child do not always mesh neatly with those planned for their classmates, and although in-service training on language impairment and language-learning activities 
is welcomed by teachers many must begin to meet a child's needs in advance of opportunities to train. The programme developed was therefore designed to offer a fast response with minimal setup and training time. Details of the series of meetings and decisions appear in Document 1; Introduction to the language support model-http://ww.strath.ac.uk/media/departments/eps/doest stt/tr/lsm/media_61623_en.pdf) and are charted in Appendix 1.

In outline, once a decision had been made that in-class language support was to be offered to a child with LI, support meeting 1 would take place between the SLT and class teacher and headteacher, with learning-support staff if relevant, to discuss what was to happen. Agreement would be reached at the meeting on which education-staff would undertake language-learning activities with a child, and the timetable for such activities. Language activities could involve class teachers, classroom support workers, learning-support teachers or a mix of staff, and time allocations would be agreed. Contact details for education and SLT staff would be exchanged.

Three documents for class teachers would be provided by the SLT at support meeting 1 . These would be the written introduction to the language support model (Document 1: Introduction to the language support model), and details on creating a communication-friendly classroom for children with language impairment (Document 2: Creating a communication friendly classroom; http:H www.strath.ac.uk/media/departments/eps/docs/slt/tr/sm/media_61624_en.pdf) and on encouraging children and teachers to monitor child comprehension (Document 3: Monitoring comprehension; http://ww.strath.ac.uk/media/departments/eps/does/slt/tr/sm/media_61625_en.pdf). These documents give background information on factors that are useful for most children with language impairment. Support meeting 1 was seen as necessary by experienced participants in order to orientate education staff towards language impairment and their role in intervention. This would be new information for many teachers. Such a meeting had been lacking in the cohort study, and potential user teachers agreed it was an essential beginning to the language-learning process.

The initial meeting was followed within three weeks by Support meeting 2, where language targets would be agreed jointly by the teacher and SLT for an individual child, and languagelearning activities would be planned. The SLT would provide details to the parent(s) or carer(s) of what these would be, using a template letter. Documents outlining how to teach the relevant area(s) of language (vocabulary, grammar, narrative: see below) would be provided according to the individual child's learning targets, and background information on the whole processes (Document 7: Development of the language support model) would be provided for general school use.

Relevant sections of the therapy manual detailing the specific language activities to be undertaken would be given by the SLT to the class teacher as soon as possible following support meeting 2 , and access to published language materials ordered via school library services. In the authority concerned, a mobile library service could deliver master copies of published materials to schools within the week, and such materials are free to photocopy for school use. The aim was that teachers could rapidly move to the delivery of relevant language activities.

Language activities would be planned for a specified number of weeks, typically 6-9 weeks, but varying for individual children.

Support meeting 2 was followed by emails confirming that intervention was taking place as planned, or noting and adjusting to any problems that arose. This was to counter the experiences of the cohort study, where schools found it difficult to sustain implementation of planned activities by giving an early alert of any problems.

A third meeting, support meeting 3, between the teacher and the SLT at the end of the planned language-learning period confirmed or adapted language targets. To do this, the SLT might want to assess child progress, perhaps using probes from the therapy manual. Targets would be monitored and updated as necessary, with support meeting 3 repeated, until the child moved on to a different 
model of service or was discharged from the SLT's care. As plans were updated, the SLT would provide details to the parent(s) or carer(s).

c Principles of development:Vocabulary, grammar, narrative: The experienced teachers also welcomed useful, practical language-learning activities that fitted into the ecology of the primary classroom. They revised documents prepared as handouts for teachers in the cohort study detailing the principles of teaching to develop vocabulary, grammar and narrative. Experienced teachers had found the cohort study versions useful, providing a context for the therapy manual activities, and suggested further improvements. The final revised versions are:

- Document 4: Principles of vocabulary development: http://www.strath.ac.uk/media/departments/eps/does/s1t/tr/sm/media_61626_en.pdf;

- Document 5: Principles of grammar development: http://w ments/eps/does/stt/tr/1sm/media_61627_en.pdf; and

- Document 6: Principles of oral narrative development: http://watrath.ac.uk/mediat departments/eps/does/stt/tr/sm/media_61628_en.pdf.

\section{Potential users' perspectives}

The language support model documents as amended by experienced users were presented to the set of potential user teachers from three education authorities and their community SLTs, who had not been involved in the cohort study. They had not seen previous drafts of materials, nor been involved in implementing specific activities from the therapy manual. They further revised the experienced user's versions at their meetings, clarifying ambiguities and discussing how the language support model and therapy manual could fit into their particular contexts.

No substantive changes were made by potential users, but they offered some final revisions. They evaluated the support model documents positively, as clear and providing ideas that were very useful for teachers. However, potential users were less certain that implementing the language support model and delivering language-learning activities would be realistic.

Table 3 shows a summary of their judgements (from 13 respondents) on the revised language support model documents. Their recorded comments indicated that they considered finding time to liaise between services - and time and personnel to undertake language work in class - to be the principal barriers to implementing language support. They considered that securing resources to carry out teaching would be difficult. In addition, despite the model being designed to deliver language intervention in a flexible way and to start at any time, they thought that budgeting and planning for language work would be required before teaching could begin, involving cross-service decision-making at the start of the school year. The model was designed to operate at the school level, but in the view of potential users it would require to be planned at SLT and educational authority level as well.

\section{Discussion}

Intervention for children with persisting LI can benefit from systematic and sustained languagelearning activities, as well as a supportive communication context. In the common UK model of school-based consultancy, children rely upon education staff to organize and deliver such activities as well as creating a communication-friendly classroom. Two previous research projects carried out by the authors suggested that gains in expressive language scores could be achieved by some 22 hours of therapy in an 'extract' therapy mode, but that these had not been replicated when the 
Table 3. Potential user teachers' evaluation of language support model documents $I-7(n=13)$

\begin{tabular}{llllll}
\hline Very & Fairly & Neutral & $\begin{array}{l}\text { Not } \\
\text { Very }\end{array}$ & Not all No \\
& & at all
\end{tabular}

Document I: Introduction:

The information is clear

85

The ideas are useful for teachers $\quad 6 \quad 6$

$\begin{array}{lll}\text { The actions suggested are realistic } & 2 & 7\end{array}$

Document 2: Creating a communication-friendly classroom:

The information is clear $\quad 12 \quad 1$

The ideas are useful for teachers $12 \quad$ I

The actions suggested are realistic II 2

Document 3: Monitoring comprehension:

The information is clear

The ideas are useful for teachers

The actions suggested are realistic

$\begin{array}{rrr}10 & 2 & 1 \\ 9 & 3 & 1 \\ 8 & 4 & 1\end{array}$

Document 4: Principles of vocabulary development:

The information is clear

The ideas are useful for teachers

The actions suggested are realistic

Document 5: Principles of grammar development:

The information is clear 8

The ideas are useful for teachers 8

The actions suggested are realistic

$\begin{array}{lll}0 & 2 & 1\end{array}$

$\begin{array}{lll}9 & 1\end{array}$

$\begin{array}{lll}9 & 3\end{array}$

Document 6: Principles of oral narrative development:

$\begin{array}{llll}\text { The information is clear } & 7 & 3 & 3\end{array}$

The ideas are useful for teachers $901 \quad 3$

$\begin{array}{llllll}\text { The actions suggested are realistic } & 8 & 2 & 2 & \text { I }\end{array}$

Document 7: Development of the language support model

The information is clear $\quad 9 \quad 2$

$\begin{array}{lllll}\text { The ideas are useful for teachers } & 5 & 4 & 1 & 2\end{array}$

$\begin{array}{lllll}\text { The actions suggested are realistic } & 4 & 4 & 3\end{array}$

intervention was passed to school staff. This appeared to be related to the fact that some teachers had not been able to find time to carry out language teaching, and had felt that undertaking such work expected too much of the teacher. There was, however, very little research into the views of classroom teachers asked to undertake language teaching, or on approaches that might fit comfortably into a primary mainstream classroom.

The evaluative research project described sought the views of teachers who had taken part in the classroom-based cohort study, and new teachers who had not, along with community SLTs. They offered a critique of the language intervention developed in the RCT and used in the cohort study, suggesting ways in which the approach could be mediated for teachers. They suggested much more discussion and information exchange between class teacher and community SLT at the start of a child's episode of language learning was needed, as the approaches used by SLTs to foster language 
learning would be entirely new to many teachers. Their expertise, applied in an iterative process of document and procedure review, then constructed a model for SLTs and teachers working together in mainstream schools with children with specific language impairment. This built upon the consultancy model by:

- clarifying co-working processes;

- incorporating joint teacher/SLT target setting;

- detailing and securing commitment to the roles of both school and SLT staff;

- developing tailored documents for teacher use, cross-referred to an existing therapy manual listing activities for children; and

- providing systematic feedback and support from SLTs as language-learning activities were implemented.

The whole process, called the 'Language support model for teachers', was felt by participants to be likely to engage teachers, and to support them as they endeavoured in turn to support children.

Participants also stressed that implementation of language work in schools would require resources to be secured, particularly staff time, and this would require high-level management decisions. The language support model would therefore fit best into settings where SLT and education services, at their top management levels, agreed such a model was an appropriate pathway for pre-defined groups of language-impaired children. Nonetheless, the time pressures described by teachers in the cohort study, and anticipated by potential user teachers in the evaluative study, are real, and require to be considered. The demands being made on classroom staff are considerable, and meeting them is far from unproblematic.

Teachers' position on managerial decision-making fits in well to much current thinking on service planning. If many language-impaired children received services using the support model, the possibility of offering training to teachers would be increased. The amount of SLT and educational staff time required to set up, monitor and evaluate language learning is determined by the model, and would allow services to be costed for commissioning purposes. In so far as the research study produced a model that participating teachers and community SLTs considered viable, it offers good potential for securing the integrity of intervention within the important area of mainstream school 'consultancy' approaches.

The study reported is however very small in scale, and participants were self-selected. It is therefore likely that they were predisposed towards valuing the roles and interventions discussed. Much further analysis of the views of classroom teachers, whose voices are seldom heard in matters of co-working, is needed to support work in education. And although taking account of classroom realities, the language support model developed here has not been systematically evaluated by large numbers of teachers or SLTs, nor assessed for efficacy, although it is in use. A formal trail of its value is required. Meantime, it is offered as an approach developed through a principled discursive process amongst classroom teachers and SLTs, as a starting-point for those attempting to develop inclusive services in mainstream primary schools.

\section{Acknowledgements}

The research project 'The development and validation of materials for use by classroom teachers working with children with primary language impairment' was funded by Forth Valley and Ayrshire \& Arran Health Boards, via the Chief Scientist Office Priorities and Needs Programme. The chief investigator was Elspeth McCartney, and the grant holders were James Boyle (University of Strathclyde), Sue Ellis (University of Strathclyde), Jane Kerr (formerly SLT Department, NHS Ayrshire \& Arran) and Mary Turnbull (SLT 
Department, Forth Valley PC NHS Trust). Thanks are given to the funders. The views and opinions expressed in this article are those of the authors, and do not necessarily reflect those of the funding bodies.

\section{References}

Boyle J, McCartney E, Forbes J, and O'Hare A (2007) A randomised controlled trial and economic evaluation of direct versus indirect and individual versus group modes of speech and language: Therapy for children with primary language impairment. Health Technology Assessment 11(25): 1-158.

Boyle J, McCartney E, O'Hare A, and Forbes J (2009) Direct versus indirect and individual versus group modes of language therapy for children with primary language impairment: Principal outcomes from a randomised controlled trial and economic evaluation. International Journal of Language and Communication Disorders 44(6): 826-46.

Department for Children, Schools and Families (DCSF) (2008) The Bercow report: A review of services for children and young people (0-19) with speech, language and communication needs. Retrieved from: http://www.dcsf.gov.uk/slcnaction/bercow-review.shtml (August 2010).

Department for Education and Science (DfES) (2001) The SEN code of practice. Annesley: DfES Publications.

Department for Education and Science (DfES) (2004) Every child matters: Next steps. Annesley: DfES.

Gascoigne M (2006) Supporting children with speech, language and communication needs within integrated children's services. Royal College of Speech and Language Therapists Position Paper. London: RCSLT.

Law J, Lindsay G, Peacey N, Gascoigne M, Soloff N, Radford J, and Band S (2002) Consultation as a model for providing speech and language therapy in schools: A panacea or one step too far? Child Language, Teaching and Therapy 18: 145-63.

Learning and Teaching Scotland (LTS) (2000) Support for learning, part three, number 7: Developing the 5-14 curriculum for pupils with language and communication disorders. Dundee: Learning and Teaching Scotland.

Learning and Teaching Scotland (LTS) (2008) Curriculum for Excellence: Literacy and English, principles and practice. Retrieved from http://www.ltscotland.org.uk/Images/literacy_english_principles_practice_ tcm4-540165.pdf (August 2010).

McCartney E, Ellis S, and Boyle J (2009) The mainstream primary school as a language-learning environment for children with language impairment: Implications of recent research. Article in a themed special issue of Journal of Research in Special Education, entitled 'social and environmental influences on childhood speech, language and communication difficulties'. Journal of Research in Special Education 9(2): 80-90.

McCartney E, Boyle J, Ellis S, Bannatyne S, and Turnbull M (in press) Indirect language therapy for children with persistent language impairment in mainstream primary schools: Outcomes from a cohort intervention. International Journal of Language and Communication Disorders,

Qualification and Curriculum Authority (QCA) (1999) Inclusion in English. Retrieved from: http://curriculum. qca.org.uk/key-stages-1-and-2/inclusion/inclusioninsubjects/inclusioninenglish/index.aspx (August 2010).

Qualification and Curriculum Authority (QCA) (2008) English Key Stage 1, Key Stage 2. Retrieved from: http://curriculum.qca.org.uk/key-stages-1-and-2/subjects/english/keystage1/index.aspx (August 2010).

Scottish Executive (2002) Standards in Scotland's Schools etc. Act 2000: Guidance On Presumption of Mainstream Education. Last modified March 2006. Retrieved from: http://www.scotland.gov.uk/ Publications/2002/05/14630/3866 (August 2010).

Scottish Executive (2004) Education (Additional Support For Learning) (Scotland) Bill [As Passed]. Edinburgh: The Stationery Office.

Semel E, Wiig E, and Secord W (2000) Clinical evaluation of language fundamentals (CELF-3 UK). 3rd edition. London: Harcourt/The Psychological Corporation. Adjusted norms published 2003.

Wechsler D (1999) Wechsler Abbreviated Scale of Intelligence (WASI). London: The Psychological Corporation. 


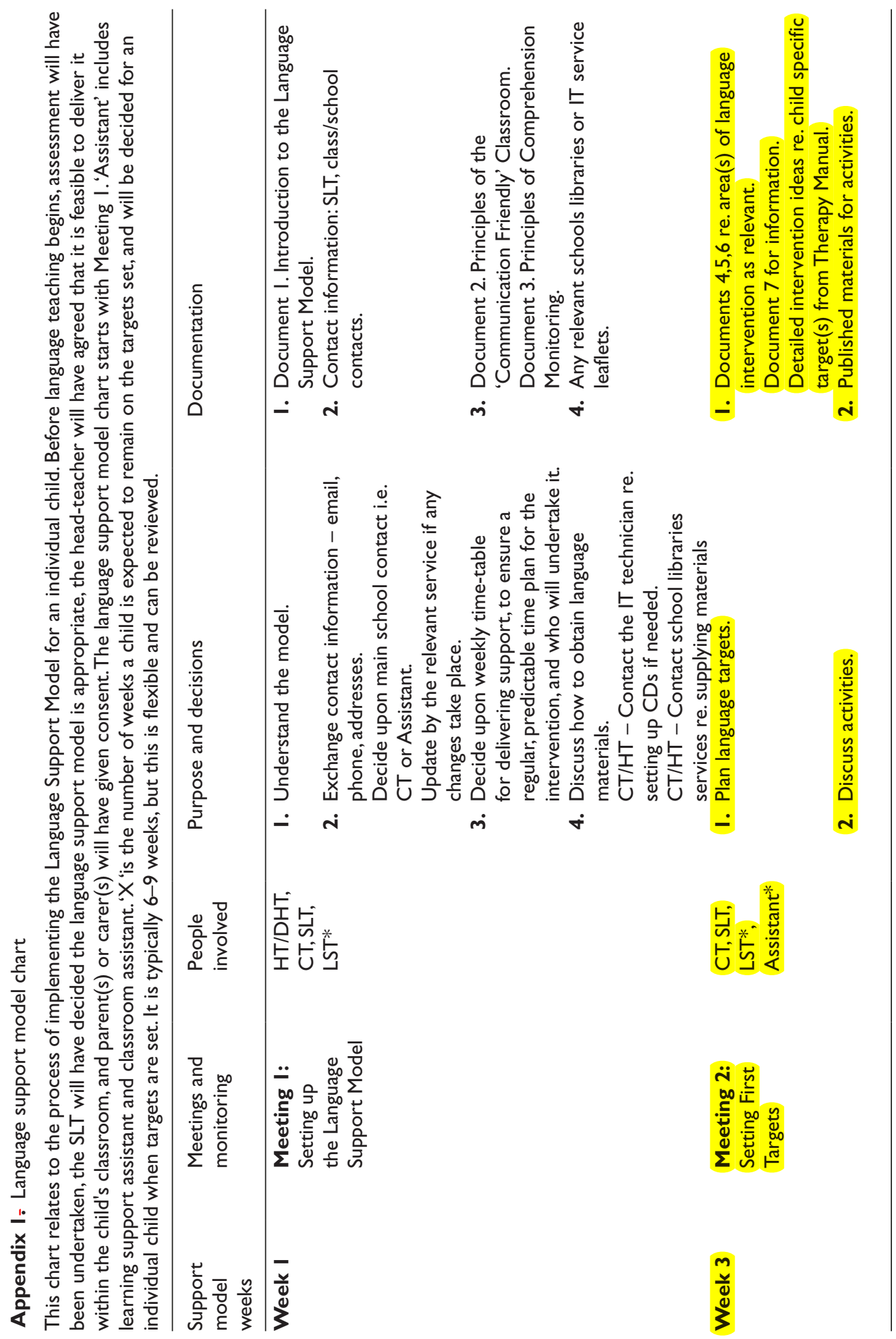




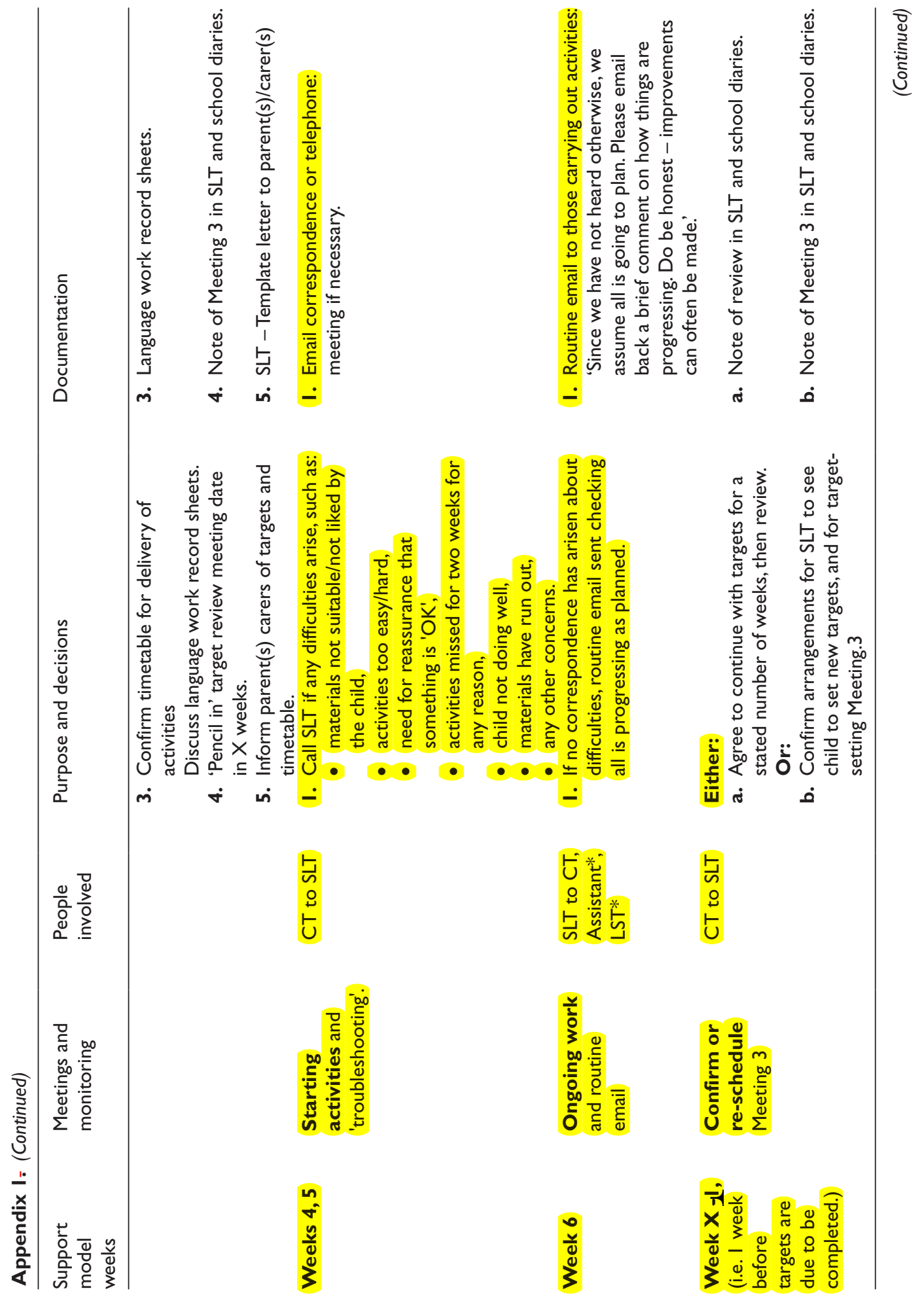




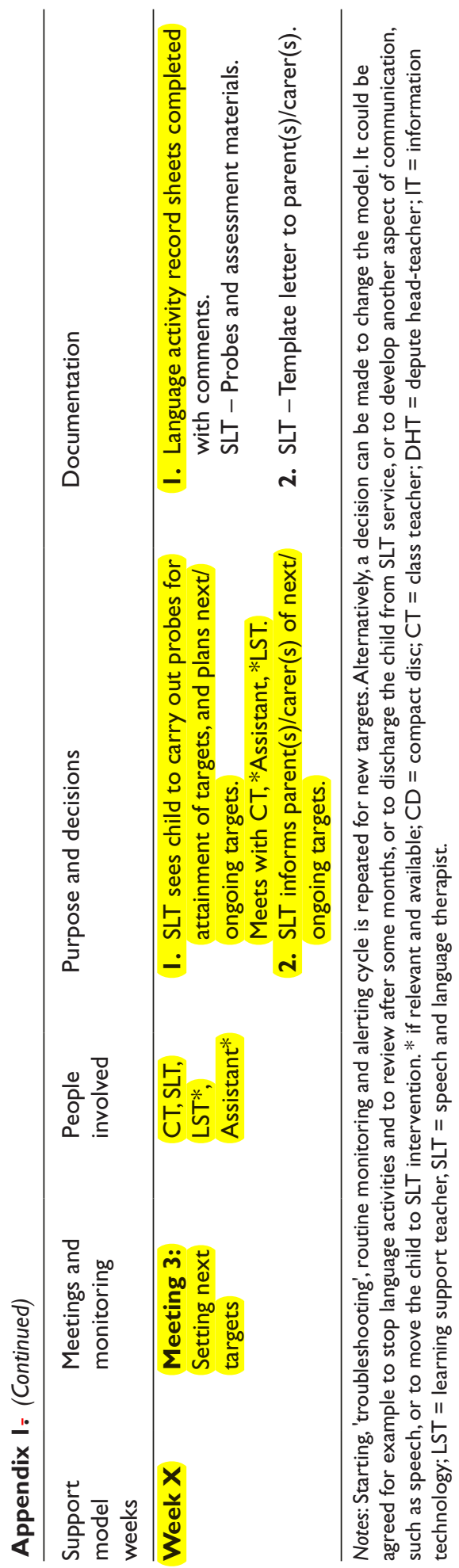

